\title{
A COMPREENSÃO LEITORA SOB A ÓTICA DA TEORIA DA RELEVÂNCIA: UM ESTUDO SOBRE A MANIPULAÇÃO DE OBJETOS DIGITAIS DE APRENDIZAGEM DA LEITURA
}

Joseane Diehl ${ }^{1}$

Kári Lúcia Forneck ${ }^{2}$

Aline Diesel ${ }^{3}$

\begin{abstract}
Resumo: Neste estudo, analisou-se o desempenho de 38 alunos do $8^{\circ}$ do Ensino Fundamental em atividades de compreensão de textos de humor presentes em objetos digitais de aprendizagem (ODA), à luz da Teoria da Relevância. Foram investigadas as interaçóes dos alunos em um questionário online, composto por 7 questóes de múltipla escolha e de associação. Cada tarefa apresentou feedbacks instrutivos que traziam para o plano da consciência o percurso cognitivo adotado no caso do acerto, e a ser adotado no caso do erro. Evidenciou-se que a produçáo de inferências decorre de um mecanismo cognitivo que requer baixo custo de processamento e alto benefício cognitivo, resultante dessa interação, tal como evidencia o Princípio da Relevância.
\end{abstract}

Palavras-chave: Compreensão. Produção de inferências. Objetos digitais de aprendizagem. Teoria da Relevância.

\section{READING COMPREHENSION UNDER THE LIGHT OF THE RELEVANCE THEORY: A STUDY ON THE HANDLING OF DIGITAL READING LEARNING OBJECTS}

\begin{abstract}
In this study, the performance of 38 students from the 8th year of Elementary Education was analyzed during activities of humor text in Digital Learning Objects (DLO) reading comprehension under the light of the Relevance Theory. The interactions were investigated through
\end{abstract}

1 Docente de Língua Portuguesa na rede privada de ensino. Graduação em Letras. Universidade do Vale do Taquari - Univates. E-mail: joseane_diehl14@hotmail.com

2 Docente do Programa de Pós-Graduação em Ensino e do Curso de Letras da Universidade do Vale do Taquari - Univates. Doutora em Letras. E-mail: kari@univates.br.

3 Docente de Língua Portuguesa na rede privada de ensino. Mestre em Ensino. Universidade do Vale do Taquari - Univates. E-mail: aline_diesel@universo.univates.br 
and online questionnaire, comprised with seven multiple choice and association questions. Each task provided instructive feedback that brought to the conscience plane the cognitive path adopted when correct and to be adopted when mistaken. It became evident that inference production yields from a cognitive mechanism that requires low processing cost and high cognitive benefit that results from such interaction, as is evident in the Relevance Principle.

Keywords: Comprehension. Inference production. Digital learning objects. Relevance Theory.

\section{Introduçáo}

Que percursos cognitivos são trilhados quando produzimos inferências? Como pensamos enquanto processamos a compreensáo de um enunciado? Neste estudo, promovemos reflexôes a partir dessas questóes norteadoras, por meio da análise de tarefas de leitura aplicadas em alunos do Ensino Fundamental em contextos de interação com objetos digitais de aprendizagem (ODA). A testagem foi composta de um conjunto de atividades virtuais com sete tarefas envolvendo a compreensão de textos humorísticos. Os ODA em questáo foram escolhidos pois promovem a aprendizagem de estratégias de leitura e trazem para o plano da consciência o percurso cognitivo exigido para a compreensão dos textos.

A fim de desenvolvermos nosso propósito, analisaremos as respostas dos estudantes à luz da Teoria da Relevância (TR), de Sperber e Wilson (1995) e Wilson e Sperber (2012), no intuito de refletir sobre os processos de compreensão leitora promovidos pela interação do leitor com textos de humor disponíveis nos ODA em questão.

\section{Teoria da Relevância, compreensáo leitora e uso de objetos digitais de aprendizagem}

A compreensão textual é um processo complexo que demanda do leitor um conjunto de habilidades cognitivas, as quais, postas em funcionamento, resultam na produção de significado através da inferenciação.

Num universo profícuo de abordagens teóricas sobre a compreensão, encontramos também a TR (SPERBER; WILSON, 1995; WILSON; SPERBER, 2012) que explica o processo inferencial não apenas do ponto de vista lógico ou linguístico, mas, em especial, sob o viés cognitivo, trazendo à tona aspectos pragmático-cognitivos da construção dos sentidos.

A TR se fundamenta no argumento de que o leitor realiza esforços - de atenção, de memória, de compreensáo - para processar a comunicaçáo desde que a julgue relevante. A relevância se sustenta na premissa de que a comunicação deve, de algum modo, render efeitos contextuais adicionais, de modo que altere ou enriqueça seu ambiente cognitivo, o que pode acontecer através do acréscimo de novos conhecimentos e crenças, ou cancelamento de velhas crenças, ou, simplesmente, uma pequena mudança no grau de reconhecimento e confiança em suas velhas crenças. 
Em outras palavras, a TR fundamenta-se na ideia de que as pessoas estão atentas aos fenômenos que lhes parecem relevantes. O Princípio da Relevância, cuja definição norteia o trabalho de Sperber e Wilson, é apresentado da seguinte maneira: "Todo ato de comunicação ostensiva comunica a presunção de sua própria relevância ótima" (SPERBER; WILSON, 1986, p. 158). Esse princípio se desdobra nas definiçóes a seguir: (a) quanto maior o efeito cognitivo obtido pelo processamento de alguma informaçáo, maior a relevância para o indivíduo que a processa; (b) quanto menor o esforço envolvido no processamento de alguma informação, maior sua relevância para o indivíduo que a processa.

$\mathrm{O} P R$ diz respeito às noçôes de efeito cognitivo e de esforço de processamento, numa relação custo/benefício, em que, de um lado, temos o pressuposto de que, em uma situação comunicativa, se busque o máximo de benefício e, de outro, que esse benefício se dê a partir do menor esforço de processamento.

Por essa razão, o princípio geral da relevância também organiza nossos interesses como leitores. Isso porque,

[...] como resultado de nossa história cognitiva, alguns tópicos em nossa memória são mais ricos em informaçóes e, mesmo sendo temporários ou permanentes, são mais acessíveis que outros, de modo que a nova informação se relaciona a eles para produzir maior efeito pelo menor esforço, ou seja, ser mais relevante (SPERBER; WILSON, 1991, p. 554).

Embora estudos sobre a TR já venham sendo desenvolvidos há décadas, percebemos que as práticas pedagógicas envolvendo a leitura e a compreensão sob a ótica da relevância ainda têm um caminho a consolidar. Isso porque o ensino da leitura, em muitos contextos pedagógicos, ainda está respaldado em atividades de decodificação e de localização de informaçóes explícitas no texto e não na produção de inferências pela relevância máxima.

Tomando a leitura como ponto central do trabalho com a linguagem, em 2014, durante a vigência do projeto de extensão $O$ ensino de estratégias de leitura: propostas de intervenção por meio de objetos digitais de aprendizagem, desenvolvido em uma instituição de Ensino Superior (RS), foram elaborados ODA que póem em foco aspectos cognitivos da compreensão leitora, entre os quais, a produção de inferências. Em Forneck, Fuchs e Bersch (2015; 2016), explicitou-se o modo como objetos digitais de aprendizagem podem ter impacto positivo na desautomatização das estratégias de leitura a serem utilizadas nas mais diferentes situaçôes de interação com texto. Em Martins et. al (2016), em decorrência de uma interface construída com o grupo de pesquisa Metodologias Ativas, vinculado ao projeto de pesquisa Mestrados para a formação de docentes: um locus de (re)construção e de aprendizagem, desenvolvido na mesma instituição, verificou-se uma melhora significativa no desempenho em leitura de estudantes que interagiram com objetos digitais de aprendizagem para o ensino da leitura, o que justificou o entendimento de que o uso de ODA pode ser considerado uma metodologia ativa de ensino. 
Por essa razão, entendemos que o uso de recursos digitais elaborados com o propósito de desenvolver habilidades em nível metacognitivo ${ }^{4}$ pode contribuir para a qualificação de metodologias de ensino inovadora.

Mas de que modo se justificam determinadas escolhas de percursos cognitivos de compreensão? A TR pode contribuir como potencial explicação para a construçáo de determinados sentidos, em contextos de interação com ODA.

A fim de ilustrarmos de que modo essa complexa interface se concretiza, apresentaremos a seguir a metodologia utilizada para a produção de dados e também uma análise dos resultados encontrados.

\section{Procedimentos Metodológicos}

Como já elucidado, neste artigo nos propomos, de um lado, a analisar o desempenho de alunos do $8^{\circ}$ do Ensino Fundamental em atividades de compreensáo leitora de textos de humor, à luz do Princípio da Relevância, e, de outro, a elucidar a importância da manipulaçáo consciente dos percursos cognitivos desempenhados em processos de compreensáo textual, mediados por objetos digitais de aprendizagem.

Para a realização da pesquisa, foram investigadas as interaçóes com objetos digitais de aprendizagem (ODA) aplicados em 38 alunos de 13 a 15 anos, de duas turmas de uma escola da rede pública do Vale do Taquari.

O ambiente virtual, elaborado na plataforma moodle, foi criado para que os alunos pudessem responder às tarefas, ficando registradas as suas respostas para cada questão e o número de tentativas dos alunos até chegar à resposta esperada, o que possibilitou analisar como os alunos compreenderam os textos, a partir das atividades. Ressaltamos que o propósito náo era avaliar a resposta correta do aluno, mas sim o caminho até a compreensão. Ou seja, verificar em que medida o aluno percebeu a intencionalidade humorística dos textos selecionados e inferiu o conteúdo implícito do humor.

Para ter acesso ao ambiente virtual, os alunos foram previamente cadastrados, de forma que cada um recebesse um código e uma senha de acesso.

Em dia previamente definido, os alunos foram levados ao laboratório de informática para que, individualmente, respondessem às atividades dos ODA, durante a aula de Língua Portuguesa.

Em relação às atividades dos ODA utilizados nesta pesquisa, é preciso mencionar que o conjunto de dez objetos digitais de aprendizagem da leitura estáo disponíveis no Repositório de Objetos de Aprendizagem da Univates (ROAU) (www.univates.br/roau) e foram elaborados, como já mencionado, no intuito de desenvolverem a compreensão leitora em nível metacognitivo. Para a presente pesquisa, foram selecionadas algumas das tarefas elaboradas para os textos de humor "Pai não entende nada" e "Velhinho Milionário", disponíveis no ROAU, e "O Louco

4 Para aprofundar essa questão, sugerimos Forneck, Fuchs e Bersch $(2015 ; 2016)$. 
e o Pinguim" e "Pneu Furado", cujas tarefas foram elaboradas especialmente para esta pesquisa. A atividade completa era composta por sete tarefas de compreensáo, em que os alunos deveriam ler os textos propostos e, a partir deles, responder às questôes conforme o seu enunciado. As questóes eram de múltipla escolha e associação, conforme apresentado a seguir.

Quadro 1 - Tarefas utilizadas como instrumento de coleta de dados

- Um biquíni novo?

As tarefas 1 e $2^{5}$ são relacionadas ao texto "Pai não entende nada"6

- É, pai.

- Você comprou um no ano passado!

- Não serve mais, pai. Eu cresci.

- Como não serve? No ano passado você tinha 14 anos, este ano tem 15. Não cresceu tanto assim.

- Não serve, pai.

- Está bem, está bem. Toma o dinheiro. Compra um biquíni maior.

- Maior não, pai. Menor.

Aquele pai, também, não entendia nada.

Tarefa 1: Qual o sentido da expressão "não serve mais" para o pai e para a filha? Arraste os personagens ao sentido que cada um dá à expressão:
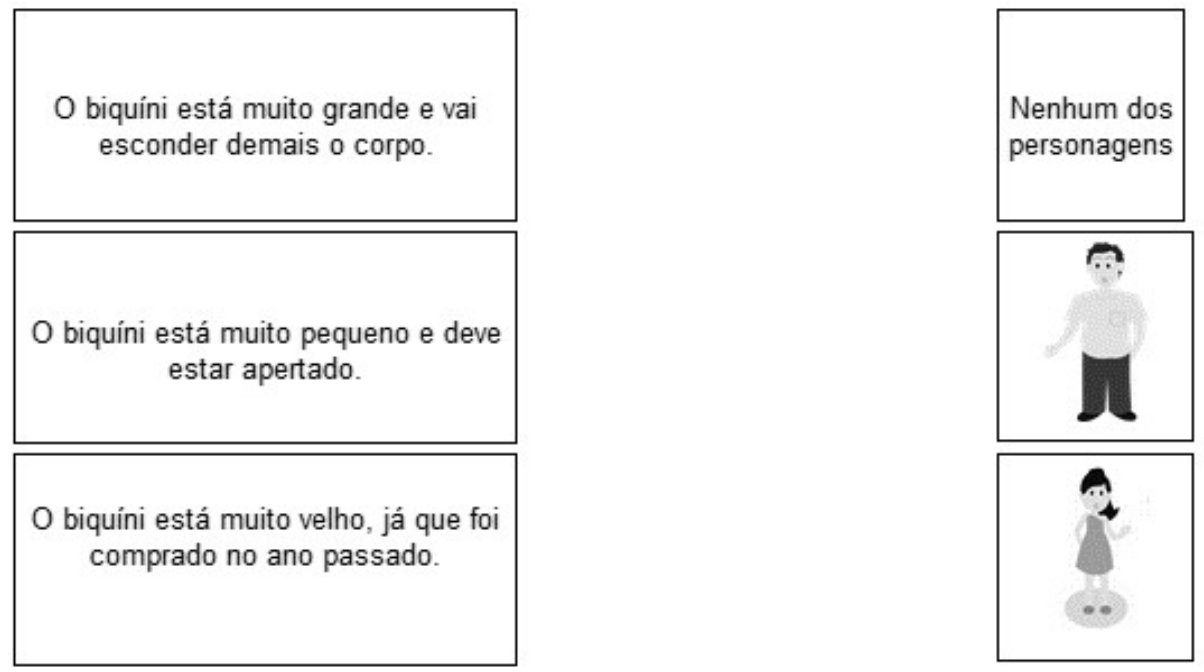

5 Atividades adaptadas do objeto digital de aprendizagem Compreensão textual 9 - Humor, disponível no Repositório de Objetos de Aprendizagem da Univates (ROAU). Disponível em: <http://www.univates.br/roau/download/144/index.htm>

6 VERISSIMO, Luis Fernando. Pai não entende nada. L\&PM, 1999. 
Tarefa 2: Clique na(s) afirmativa(s) que considerar correta(s).

A expressão "Pai não entende nada" pode significar:
a) Nenhum pai nunca entende nada.
b) Se é pai, não entende nada.
c) Os pais nunca entendem nada.
d) Este pai nunca entende nada.
e) Alguns pais náo entendem nada.
f) Somente aquele pai não entende nada.

\section{A tarefa $3^{7}$ é relacionada ao texto "Velhinho Milionário"8}

Médico otorrino (que trata das doenças dos ouvidos) atende um velhinho milionário que tinha começado a usar um aparelho de audição.

- E aí, seu Almeida, está gostando do aparelho?

- É muito bom, respondeu o velhinho.

- Sua família gostou? - Perguntou o médico.

- Ainda não contei para ninguém; mas já mudei meu testamento três vezes...

Tarefa 3: Pelo que se pode ver, a causa da mudança do testamento está no fato de o velhinho ter começado a usar o aparelho de audição. As afirmaçóes abaixo dizem respeito a sentidos possíveis para essa relação de causa e efeito, exceto:

a) Com o uso do aparelho, o velhinho passou a escutar seus familiares falarem bem dele.

b) Com o uso do aparelho, o velhinho passou a se sentir melhor.

c) Com o uso do aparelho, o velhinho pôde conhecer melhor seus familiares.

d) Com o uso do aparelho, o velhinho passou a escutar seus familiares falarem mal dele.

e) Com o uso do aparelho, o velhinho passou a escutar o que os seus familiares diziam.

\section{As tarefas 4 e 5 sáo relacionados ao texto "O Louco e o Pinguim"”}

O louco acorda de manhã e encontra um pinguim no quintal. $\mathrm{O}$ vizinho do louco, que estava espiando pelo muro, faz uma sugestão:

- Por que você não leva o pinguim para o zoológico?

- Boa ideia! Vou levar.

No dia seguinte, o vizinho encontra o louco com o pinguim no colo.

- Ué!? Você não levou o pinguim para o zoológico?

- Levei, sim. Hoje vou levá-lo ao parque de diversões e amanhã vamos ao shopping center.

7 Ver nota 2.

8 Fonte: http://www.fabulasecontos.com.br/?pg=descricao\&id=433.

9 FIZETTO, A. Meu primeiro livro de piadas. Todo Livro, 2004. 
Tarefa 4: Analise o trecho a seguir:

“- Por que você não leva o pinguim para o zoológico?

- Boa ideia! Vou levar.”

Qual o sentido de levar para o vizinho e para o louco? Arraste a palavra levar de acordo com o sentido que cada personagem dá à palavra:
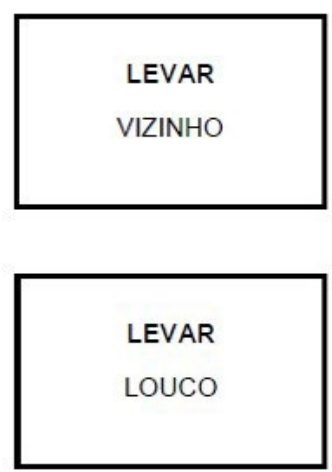

Levar o pinguim ao zoológico para passear com ele.

Levar o pinguim até o zoológico para deixa-lo lá, pois esse é o local apropriado para essa espécie de animal.

Tarefa 5: Ao encontrar o louco com o pinguim novamente no colo, o vizinho ficou surpreso. Por quê?

a) O louco não gostou de levar o pinguim ao zoológico.

b) Não é recomendado pegar pinguim no colo.

c) O louco não entendeu o que o vizinho sugeriu.

d) O louco não levou o pinguim para passear no dia anterior.

As tarefas 6 e 7 são relacionadas ao texto "Pneu Furado"10

O carro estava encostado no meio-fio, com um pneu furado. De pé ao lado do carro, olhando desconsoladamente para o pneu, uma moça muito bonitinha.

Tâo bonitinha que atrás parou outro carro e dele desceu um homem dizendo "Pode deixar". Ele trocaria o pneu.

- Você tem macaco? - perguntou o homem.

- Não - respondeu a moça.

- Tudo bem, eu tenho - disse o homem - Você tem estepe?

- Não - disse a moça.

- Vamos usar o meu - disse o homem.

E pôs-se a trabalhar, trocando o pneu, sob o olhar da moça.

Terminou no momento em que chegava o ônibus que a moça estava esperando. Ele ficou ali, suando, de boca aberta, vendo o ônibus se afastar.

Dali a pouco chegou o dono do carro.

- Puxa, você trocou o pneu pra mim. Muito obrigado.

- É. Eu... Eu não posso ver pneu furado. Tenho que trocar.

- Coisa estranha.

- É uma compulsão. Sei lá.

10 VERISSIMO, Luis Fernando. Pai não entende nada. L\&PM, 1999. 
Tarefa 6: Clique na(s) afirmativa(s) que considerar correta(s), conforme a expressão "tão bonitinha" pode significar:

Tão bonitinha...
a) que o homem decidiu parar o carro.
b) que só podia ser a dona do carro.
c) que o homem que ofereceu ajuda era borracheiro.
d) que o homem não teve nenhum interesse.
e) que o homem resolveu trocar o pneu.
f) que o homem somente teve interesse financeiro.
g) que o homem se interessou pela moça.

Tarefa 7: Qual a passagem do texto que indica que o personagem deu-se conta do equívoco que havia cometido?
a) "Dali a pouco chegou o dono do carro."
b) "- É. Eu... Eu não posso ver pneu furado. Tenho que trocar."
c) "Terminou no momento em que chegava o ônibus que a moça estava esperando".
d) "Ele ficou ali, suando, de boca aberta, vendo o onibus se afastar."
e) "É uma compulsão. Sei lá."

Fonte: elaborado pelas autoras.

Cabe ressaltar que em cada tentativa de resposta, o aluno recebia um feedback, orientando-o quanto a sua resposta: se estivesse incorreta, o aluno poderia refazer a questão, até chegar àquela que era esperada. Os feedbacks de cada tarefa foram pensados no intuito de trazer para o plano da consciência o processo de compreensáo do significado pretendido ${ }^{11}$. Ao final das atividades, cada aluno salvou e enviou as suas respostas (opção - Enviar tudo e terminar), que ficaram armazenadas no Ambiente Virtual.

\section{Descrição e análise de dados}

O tempo mínimo de realizaçáo das tarefas foi de 10 minutos e 22 segundos e o tempo máximo utilizado para responder ao questionário foi de 39 minutos e 47 segundos. Esse dado, indica diferenças significativas no tempo de processamento da compreensão durante a realizaçáo das tarefas. Como em qualquer outra atividade escolar, a compreensáo leitora também implica tempos distintos de processamento, de acordo com as particularidades do leitor.

A primeira e a segunda questôes exploraram o texto Pai não entende nada. $\mathrm{Na}$ primeira questão, os alunos tiveram que relacionar cada personagem com o que estava implícito no texto. Já na segunda, tiveram que analisar a expressão pai não entende nada e marcar as afirmativas corretas conforme o significado dessa expressão.

Conforme as Tabelas 1 e 2, o mínimo de tentativas na tarefa 1 foi uma tentativa, sendo que 10 alunos acertaram as suas respostas logo na primeira tentativa; e o máximo de tentativas foi 8 por 1 aluno somente. Na tarefa 2, o mínimo de

11 Em relação às características dos feedbacks, sugerimos Forneck, Fuchs e Bersch (2015). 
tentativas foi 1, sendo que 3 alunos acertaram logo na primeira tentativa, enquanto o máximo atingiu 44 tentativas, realizadas por um único aluno.

Tabela 1 - Mínimo e máximo de tentativas para a tarefa 1

\begin{tabular}{c|c}
\hline Quantidade de tentativas & No de alunos \\
\hline $\mathbf{1 ~ m i ́ n . ~}$ & $\mathbf{1 0}$ \\
\hline 2 & 16 \\
\hline 3 & 2 \\
\hline 4 & 2 \\
\hline 5 & 2 \\
\hline 6 & 3 \\
\hline 7 & 2 \\
\hline $\mathbf{8}$ máx. & $\mathbf{1}$ \\
\hline
\end{tabular}

Fonte: elaborada pelas autoras.

Tabela 2 - Mínimo e máximo de tentativas para a tarefa 2

\begin{tabular}{c|c}
\hline Quantidade de tentativas & No de alunos \\
\hline $\mathbf{1}$ mín. & $\mathbf{3}$ \\
\hline 2 & 11 \\
\hline 3 & 4 \\
\hline 4 & 1 \\
\hline 5 & 2 \\
\hline 6 & 2 \\
\hline 7 & 1 \\
\hline 8 & 3 \\
\hline 9 & 2 \\
\hline 11 & 1 \\
\hline 12 & 1 \\
\hline 13 & 2 \\
\hline 19 & 1 \\
\hline 20 & 1 \\
\hline 21 & 1 \\
\hline 22 & 1 \\
\hline $\mathbf{4 4}$ máx. & $\mathbf{1}$ \\
\hline
\end{tabular}

Fonte: elaborada pelas autoras. 
Com relação à tarefa 1 , era preciso que o aluno reconhecesse a relação de significação intencionada pelo pai: comprar um biquini maior - o biquíni está pequeno; e da filha: comprar um biquini menor - o biquini está grande. Dos 38 participantes, cerca de um quarto deles reconheceu de imediato a relação de relevância entre esses significados. Outros 16 alunos acertaram a resposta na segunda tentativa. Entretanto, 12 participantes provavelmente náo acionaram supostos relevantes no contexto do texto que poderiam colaborar para a construção das relaçóes de significaçáo pretendidas: o fato de a menina estar completando 15 anos e, por ser adolescente, ter uma relaçáo com o corpo diferente da esperada pelo pai, que, provavelmente, ainda a considerava criança; o fato de o título do texto indicar que o pai assumiria, no contexto comunicativo, uma atitude de incompreensão; e o fato de que relaçóes entre pais e filhos adolescentes acarretarem, como socialmente pressuposto, contextos de diálogos mal compreendidos. Embora esperássemos que a resposta correta fosse de baixo custo de processamento, considerando as pistas linguísticas explícitas no último diálogo entre pai e filha, cerca de um terço dos participantes não reconheceu a relaçáo de significado imediata o que implicou alto custo de processamento.

Com relação à tarefa 2, esperava-se que os alunos percebessem a generalização da expressão pai não entende nada e que, por acarretamento, eliminassem as alternativas que reforçam a especificaçáo dos pais, indicada pelos termos este pai, alguns pais e somente aquele pai. A tabela 2 evidencia que um conjunto significativo de alunos (19) deve ter abandonado a tarefa de perceber a generalização de sentido e, por considerar o esforço cognitivo de processamento, deixou de atentar ao processo de compreensão e passou a arriscar a resposta, com fica evidente no número de participantes que oscilou entre 5 e 44 tentativas de acerto. Além do mais, os feedbacks instruíam o participante a atentar justamente à generalização do enunciado, como se atesta em um deles: "Observe que na expressão 'Pai não entende nada' não há nenhuma palavra que especifique de qual pai se está falando. Isso implica que se está falando dos pais em geral. Algumas afirmativas que você marcou especificam um único pai ou um grupo de pais somente. Tente novamente, procurando escolher apenas afirmativas que generalizam" ${ }^{12}$. Acreditamos que o alto custo de processamento implicou baixo benefício cognitivo, o que fica evidente pelo grande número de tentativas, ainda que houvesse pistas linguísticas para a resolução da atividade.

O texto Velhinho Milionário oferece ao professor oportunidade de desenvolver habilidades de inferenciação a partir do reconhecimento de implícitos, como se pode ver no último enunciado do texto: "- Ainda não contei para ninguém; mas já mudei meu testamento três vezes...”. $\mathrm{Na}$ tarefa 3 , os alunos deveriam marcar a resposta incorreta, ou seja, o que não estava implícito no texto. Contudo, verificamos que apenas 10 alunos acertaram a tarefa em uma tentativa, embora mais uma vez entendermos a tarefa como atividade de baixo custo de processamento. Um total

12 http://www.univates.br/roau/download/144/piada02.htm 
de 14 alunos oscilou entre 4 e 5 tentativas, número esse que acreditamos ser alto, levando em consideração a baixo nível de dificuldade da tarefa.

Tabela 3 - Mínimo e máximo de tentativas para a tarefa 3

\begin{tabular}{c|c}
\hline Quantidade de tentativas & No de alunos \\
\hline $\mathbf{1 ~ m i ́ n . ~}$ & $\mathbf{1 0}$ \\
\hline 2 & 6 \\
\hline 3 & 3 \\
\hline 4 & 7 \\
\hline 5 & 7 \\
\hline 6 & 1 \\
\hline 7 & 1 \\
\hline 8 & 2 \\
\hline 9 & 0 \\
\hline $\mathbf{1 0}$ máx. & $\mathbf{1}$ \\
\hline
\end{tabular}

Fonte: elaborada pelas autoras.

O sistema do ambiente virtual também gerou uma tabela de análise de respostas, com o número e frequência de respostas. Como observamos na tabela seguinte (Tabela 4), um percentual consideravelmente elevado de alunos, na primeira tentativa, marcou alguma resposta que remete efetivamente à causa da mudança de testamento, indicadas pelas 4 últimas alternativas da tabela a seguir. Porém, o enunciado da tarefa solicitava que o estudante marcasse a alternativa que não estivesse de acordo com o texto: "Com o uso do aparelho, o velhinho passou a se sentir melhor". Entendemos, a partir desse dado, que, numa primeira tentativa, muitos alunos não levaram em consideração a natureza do enunciado da tarefa. Em geral, é mais relevante para um aluno, em contextos de tarefas com múltiplas escolhas, assinalar a resposta correta e não aquela que contém uma exceção. Porém, considerando que 19 alunos chegaram ao acerto depois de 4 a 10 tentativas, não se pode dizer que desatençáo seja apenas a razão do erro. Provavelmente, não acionaram, por ordem de acessibilidade, os supostos relevantes para o contexto de significação:

(1) Testamentos indicam como os bens serão distribuídos entre os familiares.

(2) Conhecer bem os familiares ajuda na tomada de decisão sobre a distribuição dos bens em testamento.

(3) Ouvir o que falam os familiares dá evidências de sua relação - boa ou ruim - com o velhinho dono do testamento.

Acessar o conjunto desses supostos é necessário para garantir a relevância máxima do texto. Como se vê, nas Tabelas 3 e 4, um conjunto significativo de estudantes não acessou esses supostos. 
Tabela 4 - Análise das respostas da tarefa 3

\begin{tabular}{l|c|c}
\hline \multicolumn{1}{c|}{ Resposta do modelo } & No de tentativas & Frequência \\
\hline $\begin{array}{l}\text { Com o uso do aparelho, o velhinho passou a se sentir } \\
\text { melhor. }\end{array}$ & 34 & $87,18 \%$ \\
\hline $\begin{array}{l}\text { Com o uso do aparelho, o velhinho passou a escutar seus } \\
\text { familiares falarem bem dele. }\end{array}$ & 21 & $53,85 \%$ \\
\hline $\begin{array}{l}\text { Com o uso do aparelho, o velhinho pôde conhecer } \\
\text { melhor seus familiares. }\end{array}$ & 20 & $51,28 \%$ \\
\hline $\begin{array}{l}\text { Com o uso do aparelho, o velhinho passou a escutar o } \\
\text { que os seus familiares diziam. }\end{array}$ & 25 & $82,10 \%$ \\
\hline $\begin{array}{l}\text { Com o uso do aparelho, o velhinho passou a escutar seus } \\
\text { familiares falarem mal dele. }\end{array}$ & $32,05 \%$ \\
\hline
\end{tabular}

Fonte: elaborada pelas autoras.

As tarefas 4 e 5 exploraram o texto $\mathrm{O}$ louco e o pinguim. Na tarefa 4 , os alunos tiveram que relacionar cada personagem com sentido da palavra levar, conforme o texto sugere. $\mathrm{Na}$ tarefa 5 , os alunos tiveram que marcar o porquê da surpresa do personagem, conforme estava implícito no texto.

Podemos verificar, conforme a Tabela 5 , que os alunos não tiveram dificuldade em associar os sentidos do polissêmico levar aos seus respectivos enunciadores. $\mathrm{O}$ humor da piada está justamente na compreensão dessa distinção semântica. Já na Tabela 6, fica evidente o baixo custo de processamento para a compreensáo da razáo da ambiguidade do verbo levar: 31 estudantes compreenderam que $O$ louco não reconheceu o que o vizinho sugeriu.

Tabela 5 - Mínimo e máximo de tentativas para a tarefa 4

\begin{tabular}{c|c}
\hline Quantidade de tentativas & No de alunos \\
\hline $\mathbf{1}$ mín. & $\mathbf{1 9}$ \\
\hline 2 & 13 \\
\hline 3 & 4 \\
\hline 4 & 0 \\
\hline 5 & 1 \\
\hline 6 máx. & $\mathbf{1}$ \\
\hline
\end{tabular}

Fonte: elaborada pelas autoras. 
Tabela 6 - Mínimo e máximo de tentativas para a tarefa 5

\begin{tabular}{c|c}
\hline Quantidade de tentativas & No de alunos \\
\hline $\mathbf{1}$ mín. & $\mathbf{3 1}$ \\
\hline 2 & 4 \\
\hline 3 & 1 \\
\hline 4 & 0 \\
\hline 5 & 1 \\
\hline 6 máx. & $\mathbf{1}$ \\
\hline
\end{tabular}

Fonte: elaborada pelas autoras.

$\mathrm{Na}$ Tabela 7, podemos analisar as respostas dos alunos, o que confirma que poucos alunos tiveram dificuldade na tarefa 5 . O alto índice de acerto na tarefa 4 implicou também alto índice de acerto na tarefa 5 . Em outras palavras, uma vez reconhecidos os sentidos do verbo levar e associados os sentidos especificamente ao louco ou ao vizinho, a mais relevante resposta na tarefa 5 só poderia ser que o louco não teria entendido o que o vizinho havia sugerido. Como não poderíamos deixar de assinalar, apesar da facilidade da tarefa 5, ainda assim, a relação de causa e efeito não foi a mais relevante para alguns dos participantes da atividade. $\mathrm{O}$ que teriam pensado os estudantes que assinalaram a alternativa Náo é recomendado pegar pinguim no colo? Da mesma forma, qual o percurso cognitivo adotado por aqueles que assinalaram $O$ louco não levou o pinguim para passear e O louco não gostou de levar o pinguim para passear, considerando que o texto da piada finaliza com a afirmação do louco: “- Levei [o pinguim para o zoológico], sim. Hoje vou levá-lo ao parque de diversóes e amanhã vamos ao shopping center”. Ora, além de afirmar que levou o pinguim ao zoológico, o louco também indica que iria levá-lo a outros espaços de lazer. Considerando o enunciado da tarefa Ao encontrar o louco com o pinguim novamente no colo, o vizinho ficou surpreso. Por quê?, parece-nos que a escolha por essas alternativas revela que, para alguns estudantes, levar em consideração elementos explícitos nos enunciados e construir uma relaçáo de sentido sem reconhecer os implícitos do texto de humor ainda é a significação mais relevante, por ser a menos custosa. Em outras palavras, o alto custo de processamento de uma inferência implícita pode tornar, para um conjunto considerável de alunos, a significação humorística irrelevante. Esse dado em particular revela a longa caminhada que ainda deve ser trilhada em termos de reconhecimento da relevância dos sentidos em cada contexto de significação. 
Tabela 7 - Análise das respostas da tarefa 5

\begin{tabular}{l|c|c}
\hline \multicolumn{1}{c|}{ Resposta do modelo } & No de tentativas & Frequência \\
\hline O louco não gostou de levar o pinguim ao zoológico. & 6 & $15,38 \%$ \\
\hline O louco não levou o pinguim para passear no dia anterior. & 6 & $15,38 \%$ \\
\hline O louco não entendeu o que o vizinho sugeriu. & 38 & $97,44 \%$ \\
\hline Não é recomendado pegar pinguim no colo. & 4 & $10,26 \%$ \\
\hline
\end{tabular}

Fonte: elaborada pelas autoras.

Nas tarefas 6 e 7, os alunos teriam que analisar o texto Pneu Furado. Conforme os dados das Tabelas 8 e 9, os alunos tiveram bastante dificuldade na tarefa 6, visto que tinham que analisar a expressão tão e marcar as alternativas que davam sentido a essa palavra, conforme o texto. Já na tarefa 7 , os alunos tinham que analisar qual frase do texto indicava que o personagem tinha se dado conta do equívoco que havia cometido.

$\mathrm{Na}$ tarefa 6, o mínimo de tentativas foi uma, realizada por 2 alunos. A média ficou entre 2 até 13 tentativas, e um aluno tentou por 17 vezes chegar à resposta correta. Nessa etapa, evidenciamos que vários participantes tiveram dificuldade em encontrar as alternativas corretas.

Tabela 8 - Mínimo e máximo de tentativas para a tarefa 6

\begin{tabular}{c|c}
\hline Quantidade de tentativas & No de alunos \\
\hline $\mathbf{1}$ mín. & $\mathbf{2}$ \\
\hline 2 & 7 \\
\hline 3 & 6 \\
\hline 4 & 7 \\
\hline 5 & 3 \\
\hline 6 & 1 \\
\hline 7 & 2 \\
\hline 8 & 1 \\
\hline 9 & 3 \\
\hline 10 & 1 \\
\hline 11 & 1 \\
\hline 12 & 1 \\
\hline 13 & 2 \\
\hline $\mathbf{1 7}$ máx. & $\mathbf{1}$ \\
\hline
\end{tabular}

Fonte: elaborada pelas autoras.

Pelo que se depreende da Tabela 9, uma das respostas corretas que o homem se interessou pela moça foi a alternativa mais marcada pelos alunos já em sua 
primeira tentativa. Consideramos, a partir desse ângulo, que os alunos poderiam ter compreendido o texto; entretanto não conseguiram identificar as demais alternativas que se relacionavam à primeira e que também eram verdadeiras. Porém, mais do que reconhecer os acertos, a tabela 9 revela também que houve muitas tentativas na construção de sentidos não autorizados pelo texto, como a) Tão bonitinha que o homem não teve nenhum interesse; b) Tão bonitinha que o homem somente teve interesse financeiro; c) Tão bonitinha que só podia ser a dona do carro; d) Tẫo bonitinha que o homem que ofereceu ajuda era borracheiro.

Duas delas, a alternativa $\mathrm{b}$ que foi assinalada 31 vezes e a alternativa $\mathrm{c}$ que foi assinalada 107 vezes, revelam uma significação construída na associação entre beleza, riqueza e inaptidão. Para os alunos que assinalaram essa alternativa como verdadeira, os supostos acessados devem ter sido os seguintes:

(1) Mulheres bonitas têm mais chances de possuírem bens de valor.

(2) Mulheres bonitas não conseguem trocar pneus de carro sozinhas.

Caso nossa hipótese seja verdadeira, o percurso cognitivo desenvolvido nesses casos revela exatamente o que prevê a TR: a significação é construída quando render o enriquecimento do ambiente cognitivo do leitor, por meio, no caso em análise, do reconhecimento e da validação de suas velhas crenças. Em outras palavras, o baixo custo de processamento - reconhecimento e validação de suas crenças - rende alto benefício decorrente desse processamento. Esse dado revela que o processo inferencial do qual se produz a significação sempre requererá o recrutamento do ambiente cognitivo já construído pelo leitor. Suas crenças, ainda que questionáveis, sempre servirão como ponto de partida para a significação, porque são os supostos mais relevantes na produção de inferências.

Tabela 9 - Análise das respostas da tarefa 6

\begin{tabular}{l|c|c}
\hline \multicolumn{1}{c|}{ Resposta do modelo } & No de tentativas & Frequência \\
\hline que o homem náo teve nenhum interesse. & 23 & $58,97 \%$ \\
\hline que o homem resolveu trocar o pneu. & 89 & $228,21 \%$ \\
\hline que o homem somente teve interesse financeiro. & 31 & $79,49 \%$ \\
\hline que o homem decidiu parar o carro. & 72 & $184,62 \%$ \\
\hline que só podia ser a dona do carro. & 107 & $274,36 \%$ \\
\hline que o homem se interessou pela moça. & 138 & $353,85 \%$ \\
\hline que o homem que ofereceu ajuda era borracheiro. & 32 & $82,05 \%$ \\
\hline
\end{tabular}

Fonte: elaborada pelas autoras.

$\mathrm{Na}$ questão 7, 11 alunos realizaram uma tentativa, o mesmo número de alunos realizou duas tentativas e somente 1 aluno tentou 7 vezes. Os alunos tinham de perceber que ter ficado "ali, suando, de boca aberta, vendo o ônibus se afastar" revela o momento em que, estupefato, o homem que havia trocado o pneu 
furado reconheceu seu equívoco. A tabela 10 evidencia que 16 alunos somente reconheceram essa significação entre a terceira e a sétima tentativas.

Tabela 10 - Mínimo e máximo de tentativas para a tarefa 7

\begin{tabular}{c|c}
\hline Quantidade de tentativas & No de alunos \\
\hline $\mathbf{1 ~ m i ́ n . ~}$ & $\mathbf{1 1}$ \\
\hline 2 & 11 \\
\hline 3 & 4 \\
\hline 4 & 5 \\
\hline 5 & 4 \\
\hline 6 & 2 \\
\hline 7 máx. & $\mathbf{1}$ \\
\hline
\end{tabular}

Fonte: elaborada pelas autoras.

A Tabela 11 apresenta, de uma forma mais específica, a análise de cada aluno e de cada tarefa, como também a identificação das tarefas em que os alunos tiveram maior dificuldade. Como podemos analisar na tabela, os números que estão marcados com "i" são as tarefas não finalizadas, ou seja, salvas de forma incompleta. A tabela está dividida em duas partes: quantidades de tentativas em cada tarefa e tarefa com mais dificuldade. Assim, os dados apresentam especificamente a quantidade de tentativas para cada tarefa para cada aluno. Já na análise das tarefas com mais dificuldade, as marcaçóes foram identificadas com o maior número de tentativas até $\mathrm{o}$ acerto e também as tarefas que foram deixadas incompletas.

A Tabela 11 revela que, dos 38 alunos pesquisados, 15 alunos salvaram o questionário incompleto, sendo que os alunos poderiam refazer as questóes quantas vezes fossem necessárias, até chegar à resposta correta.

Além disso, verificamos que as tarefas 2 e 6 foram as mais difíceis. Nessas tarefas, os alunos deveriam encontrar mais de uma resposta correta. Esse dado pode evidenciar que esse tipo de tarefa não é muito trabalhado em sala de aula. As atividades mais comuns são as que imitam questôes de concurso, ou de vestibular, em que uma tarefa tem somente uma afirmativa (resposta) correta, e todas as outras incorretas.

Tabela 11 - Análise de dados

\begin{tabular}{c|c|c|c|c|c|c|c|c|c|c|c|c|c|c}
\hline \multirow{2}{*}{ Aluno } & \multicolumn{1}{c|}{ Quantidade de tentativas em cada } & \multicolumn{1}{c}{ Tarefa com mais dificuldade } \\
\hline & 1 & 2 & 3 & 4 & 5 & 6 & 7 & 1 & 2 & 3 & 4 & 5 & 6 & 7 \\
\hline Aluno 1 & 2 & $2 \mathrm{i}$ & 3 & 1 & 1 & 4 & 1 & & $\mathrm{x}$ & $\mathrm{x}$ & & & $\mathrm{x}$ & \\
\hline Aluno 2 & $2 \mathrm{i}$ & $2 \mathrm{i}$ & 1 & 1 & 1 & $9 \mathrm{i}$ & $2 \mathrm{i}$ & $\mathrm{x}$ & $\mathrm{x}$ & & & & $\mathrm{x}$ & $\mathrm{x}$ \\
\hline Aluno 3 & 2 & $2 \mathrm{i}$ & $2 \mathrm{i}$ & $2 \mathrm{i}$ & 1 & $2 \mathrm{i}$ & $2 \mathrm{i}$ & & $\mathrm{x}$ & $\mathrm{x}$ & $\mathrm{x}$ & & $\mathrm{x}$ & $\mathrm{x}$ \\
\hline
\end{tabular}




\begin{tabular}{|c|c|c|c|c|c|c|c|c|c|c|c|c|c|c|}
\hline \multirow{2}{*}{$\begin{array}{c}\text { Aluno } \\
\text { Aluno } 4\end{array}$} & \multicolumn{7}{|c|}{$\begin{array}{c}\text { Quantidade de tentativas em cada } \\
\text { tarefa }\end{array}$} & \multicolumn{7}{|c|}{ Tarefa com mais dificuldade } \\
\hline & 2 & 13 & 8 & 3 & 1 & 2 & 2 & & $\mathrm{x}$ & $\mathrm{x}$ & $\mathrm{x}$ & & & \\
\hline Aluno 5 & 2 & 5 & 4 & 1 & 1 & 4 & 2 & & $\mathrm{x}$ & $\mathrm{x}$ & & & $\mathrm{x}$ & \\
\hline Aluno 6 & 1 & 3 & 5 & 1 & 1 & 4 & 5 & & $\mathrm{x}$ & $\mathrm{x}$ & & & $\mathrm{x}$ & $\mathrm{x}$ \\
\hline Aluno 7 & 1 & $2 \mathrm{i}$ & 1 & 1 & 1 & $2 \mathrm{i}$ & 1 & & $\mathrm{x}$ & & & & $\mathrm{x}$ & \\
\hline Aluno 8 & 5 & 6 & 4 & 2 & 1 & 6 & 1 & $\mathrm{x}$ & $\mathrm{x}$ & $\mathrm{x}$ & & & $\mathrm{x}$ & \\
\hline Aluno 9 & 2 & 13 & 5 & 1 & 1 & 4 & 4 & & $\mathrm{x}$ & $\mathrm{x}$ & & & $\mathrm{x}$ & $\mathrm{x}$ \\
\hline Aluno 10 & 1 & 2 & 4 & 1 & 1 & 2 & 2 & & & $\mathrm{x}$ & & & & \\
\hline Aluno 11 & $2 \mathrm{i}$ & $3 \mathrm{i}$ & 1 & 1 & 1 & $9 \mathrm{i}$ & 7 & & $\mathrm{x}$ & & & & $\mathrm{x}$ & $\mathrm{x}$ \\
\hline Aluno 12 & $1 \mathrm{i}$ & 2 & $5 \mathrm{i}$ & 1 & 1 & 4 & 3 & $\mathrm{x}$ & & $\mathrm{x}$ & & & $\mathrm{x}$ & $\mathrm{x}$ \\
\hline Aluno 13 & 1 & 5 & 3 & 1 & 1 & 13 & 1 & & $\mathrm{x}$ & $\mathrm{x}$ & & & $\mathrm{x}$ & \\
\hline Aluno 14 & 3 & 7 & 10 & 6 & 1 & 3 & 2 & $\mathrm{x}$ & $\mathrm{x}$ & $\mathrm{x}$ & $\mathrm{x}$ & & $\mathrm{x}$ & \\
\hline Aluno 15 & 2 & 9 & 5 & 1 & 1 & 3 & 4 & & $\mathrm{x}$ & $\mathrm{x}$ & & & $\mathrm{x}$ & $\mathrm{x}$ \\
\hline Aluno 16 & 1 & 20 & 1 & 3 & 2 & 7 & 4 & & $\mathrm{x}$ & & $\mathrm{x}$ & & $\mathrm{x}$ & $\mathrm{x}$ \\
\hline Aluno 17 & 1 & 1 & $1 \mathrm{i}$ & $2 \mathrm{i}$ & $1 \mathrm{i}$ & $1 \mathrm{i}$ & 2 & & & $\mathrm{x}$ & $\mathrm{x}$ & $\mathrm{x}$ & $\mathrm{x}$ & \\
\hline Aluno 18 & 2 & 4 & 1 & 1 & 1 & 12 & 1 & & $\mathrm{x}$ & & & & $\mathrm{x}$ & \\
\hline Aluno 19 & 1 & 3 & 5 & 1 & 2 & 3 & 5 & & $\mathrm{x}$ & $\mathrm{x}$ & & & $\mathrm{x}$ & $\mathrm{x}$ \\
\hline Aluno 20 & 1 & 8 & 3 & 1 & 1 & 3 & 5 & & $\mathrm{x}$ & $\mathrm{x}$ & & & $\mathrm{x}$ & $\mathrm{x}$ \\
\hline Aluno 21 & 8 & 2 & 8 & 1 & 1 & 5 & 1 & $\mathrm{x}$ & & $\mathrm{x}$ & & & $\mathrm{x}$ & \\
\hline Aluno 22 & 2 & 2 & 4 & 2 & 1 & $2 \mathrm{i}$ & 1 & & & $\mathrm{x}$ & & & $\mathrm{x}$ & \\
\hline Aluno 23 & 6 & $1 \mathrm{i}$ & $1 \mathrm{i}$ & 1 & 1 & $1 \mathrm{i}$ & 3 & $\mathrm{x}$ & $\mathrm{x}$ & $\mathrm{x}$ & & & $\mathrm{x}$ & $\mathrm{x}$ \\
\hline Aluno 24 & $6 \mathrm{i}$ & $9 \mathrm{i}$ & 5 & 1 & 1 & $3 \mathrm{i}$ & 1 & $\mathrm{x}$ & $\mathrm{x}$ & $\mathrm{x}$ & & & $\mathrm{x}$ & \\
\hline Aluno 25 & 2 & 22 & 1 & 2 & 1 & 4 & 2 & & $\mathrm{x}$ & & & & $\mathrm{x}$ & \\
\hline Aluno 26 & 1 & 2 & 4 & 2 & 2 & 3 & 3 & & & $\mathrm{x}$ & & & $\mathrm{x}$ & $\mathrm{x}$ \\
\hline Aluno 27 & 7 & 2 & 4 & 1 & 3 & 5 & 6 & $\mathrm{x}$ & & $\mathrm{x}$ & & $\mathrm{x}$ & $\mathrm{x}$ & $\mathrm{x}$ \\
\hline Aluno 28 & 2 & 19 & 2 & 2 & 1 & 8 & 3 & & $\mathrm{x}$ & & & & $\mathrm{x}$ & $\mathrm{x}$ \\
\hline Aluno 29 & 2 & 6 & 2 & 2 & 1 & 5 & 2 & & $\mathrm{x}$ & & & & $\mathrm{x}$ & \\
\hline Aluno 30 & 2 & $1 \mathrm{i}$ & 5 & 2 & 1 & 11 & 2 & & $\mathrm{x}$ & $\mathrm{x}$ & & & $\mathrm{x}$ & \\
\hline Aluno 31 & 7 & 21 & 2 & 5 & 1 & 17 & 4 & $\mathrm{x}$ & $\mathrm{x}$ & & $\mathrm{x}$ & & $\mathrm{x}$ & $\mathrm{x}$ \\
\hline Aluno 32 & 4 & 8 & 6 & 2 & 1 & 7 & 1 & $\mathrm{x}$ & $\mathrm{x}$ & $\mathrm{x}$ & & & & $\mathrm{x}$ \\
\hline Aluno 33 & $2 \mathrm{i}$ & $2 \mathrm{i}$ & 2 & 2 & 1 & $2 \mathrm{i}$ & 2 & & $\mathrm{x}$ & & & & $\mathrm{x}$ & \\
\hline Aluno 34 & 4 & $12 \mathrm{i}$ & 2 & $2 \mathrm{i}$ & 5 & $10 \mathrm{i}$ & 6 & $\mathrm{x}$ & $\mathrm{x}$ & & $\mathrm{x}$ & $\mathrm{x}$ & $\mathrm{x}$ & $\mathrm{x}$ \\
\hline Aluno 35 & 5 & $3 \mathrm{i}$ & 1 & 3 & 2 & $13 \mathrm{i}$ & 4 & $\mathrm{x}$ & $\mathrm{x}$ & & $\mathrm{x}$ & & $\mathrm{x}$ & $\mathrm{x}$ \\
\hline Aluno 36 & 6 & 11 & 1 & 2 & 6 & 4 & 1 & $\mathrm{x}$ & $\mathrm{x}$ & & & $\mathrm{x}$ & $\mathrm{x}$ & \\
\hline Aluno 37 & 3 & 44 & 4 & 3 & 1 & 2 & 1 & $\mathrm{x}$ & $\mathrm{x}$ & $\mathrm{x}$ & $\mathrm{x}$ & & & \\
\hline Aluno 38 & 2 & $8 \mathrm{i}$ & 7 & 1 & 1 & $9 \mathrm{i}$ & 5 & & $\mathrm{x}$ & $\mathrm{x}$ & & & $\mathrm{x}$ & $\mathrm{x}$ \\
\hline
\end{tabular}

Fonte: elaborada pelas autoras. 
Como já elucidado, além de analisar o desempenho de alunos do $8^{\circ}$ do Ensino Fundamental em atividades de compreensão leitora de textos de humor, à luz da TR, o que foi feito até aqui, neste artigo também nos propusemos a elucidar a importância da manipulação consciente dos percursos cognitivos desempenhados em processos de compreensão textual, mediados por objetos digitais de aprendizagem.

Acerca do segundo propósito, entendemos que o uso de recursos digitais elaborados no intuito de desenvolver habilidades em nível metacognitivo pode contribuir para a qualificação de açóes de ensino, visto que os estudantes são expostos a situaçóes de aprendizagem atípicas. Em Vicari, Forneck e Martins (2018), por exemplo, evidenciou-se que os estudantes sentem-se motivados a realizarem atividades de compreensão leitora em ambientes digitais.

Com relação à tentativa de articular o aprimoramento da compreensão leitura com os ODA questionamos: de que modo se justificam determinadas escolhas de percursos cognitivos de compreensão? Em resposta a tal questionamento, entendemos que a TR pode contribuir como potencial explicação para a construçáo de determinados sentidos, também em contextos de interação com ODA.

Convém destacar, ainda, a relevância de explorar o gênero piada nas aulas, pois exige a capacidade do leitor de realizar inferências a partir de implícitos, de elementos polissêmicos e de aspectos pragmáticos. Esse tópico mereceria uma demorada análise, mas, dada a natureza constrita deste texto, não nos deteremos nessa questão ${ }^{13}$. Apenas mencionaremos que, durante a aplicaçáa do testequestionário, muitos alunos expressaram contentamento ao realizar a leitura dos textos, o que tornou a atividade mais prazerosa e descontraída. Ademais, no caso das piadas, o sorriso pode ser um sinal de compreensão textual.

\section{Consideraçóes finais}

Neste estudo analisamos, por meio da aplicação de um questionário virtual, o desempenho de alunos do $8^{\circ}$ do Ensino Fundamental diante de atividades de compreensão de textos de humor, à luz da TR.

Ao final da análise dos dados, evidenciamos que a produção de inferências é resultado de um mecanismo cognitivo de acesso aos supostos relevantes em cada contexto linguístico e da manipulação desses supostos aos contextos linguísticos para a construçáo da significaçáo mais relevante, evidenciando uma relação de baixo custo de processamento e alto benefício de significação, tal como proposto pela TR - aporte teórico escolhido para a explicação dos resultados obtidos.

Além do mais, a manipulaçáo de objetos digitais de aprendizagem que trazem para o plano da consciência o caminho inferencial traz benefícios tanto aos estudantes quanto aos professores. De um lado, para os alunos, os ODA podem contribuir para uma aprendizagem autônoma e significativa; de outro, promovem o

13 Sugerimos a leitura de Goldnadel e Oliveira (2009). 
desenvolvimento de práticas de ensino diferenciadas, uma vez que o professor tem acesso não somente aos resultados das tarefas realizadas pelos alunos, mas também, ao detalhamento do processo de interaçáo com os ODA durante a produção de sentido.

Por fim, este estudo contribui, ainda, como uma sugestão aos professores para desenvolverem práticas escolares mais produtivas, a partir da compreensão de textos humorísticos e do uso de objetos digitais de aprendizagem para o ensino da leitura focado nos processos inferenciais.

\section{Referências}

GOLDNADEL, M; OLIVEIRA, R de C. Contribuiçóes da Teoria da Relevância para a prática de interpretação de textos: uma ilustração por meio de textos de humor. Linguagem \& Ensino, v.12, n.1, p.33-48, 2009. Disponível em http://www.rle.ucpel.tche. br/index.php/rle/article/view/89/61. Acesso em: 15 out 2018.

FORNECK, K. L.; FUCHS, J. T.; BERSCH, M. E. Um click na leitura: o ensino da leitura por meio de objetos digitais de aprendizagem. Prolíngua (João Pessoa), v. 11, n. 1, p. 51-60, 2016. Disponível em: http://www.periodicos.ufpb.br/ojs/index.php/prolingua/ article/view/30630. Acesso em: 18 mar. 2019.

FORNECK, K. L.; FUCHS, J. T.; BERSCH, M. E. Objetos digitais de aprendizagem para o ensino e a aprendizagem da leitura. Revista Linguística, v. 11, p. 207-227, 2015. Disponível em: https://revistas.ufrj.br/index.php/rl/article/view/4510. Acesso em: 18 mar. 2019.

MARTINS, S. N.; FORNECK, K. L.; DIESEL, A.; BUBLITZ, G. K. Digital objects for the learning of reading: An active teaching methodology. Calidoscópio (Online), v. 14, n.3, p. 413-422, 2016. Disponível em: http://revistas.unisinos.br/index.php/calidoscopio/ article/view/cld.2016.143.05 Acesso em: 18 mar. 2019.

SPERBER, D.; WILSON, D. Relevance: communication and cognition. 2 ed. Cambridge, USA: Blackwell, 1995.

VICARI, P. L., FORNECK, K. L. e MARTINS, S. N. A leitura em um click: percepçóes de estudantes do $7^{\circ}$ ano do ensino fundamental sobre sua interaçáo com objetos digitais de aprendizagem da leitura. Revista Educaonline, 12, 29-44, 2018. Disponível em: http://www.latec.ufrj.br/revistas/index. php?journal=educaonline\&page $=$ article\&op=view\&path\%5B\%5D=1037 Acesso em: 29 jul. 2019.

WILSON, D.; SPERBER, D. Meaning and Relevance. Cambridge: Cambridge University Press, 2012, E-book. 